

\title{
CADEIA DE VALOR DA REDE DE SEMENTES DO XINGU: ELABORAÇÃO DE DIRECIONAMENTO ESTRATÉGICO E GESTÃO DE RISCOS BASEADOS NOS REQUISITOS DA NORMA ISO 9001:2015 E ISO 3100:2018
}

\author{
XINGU SEED NETWORK VALUE CHAIN: ELABORATION OF STRATEGIC DIRECTION \\ AND RISK MANAGEMENT BASED ON THE REQUIREMENTS OF ISO 9001:2015 AND \\ ISO 3100:2018
}

iD Valeria Santos Guimarães ${ }^{1}$

iD Fernando Zaidan²

\begin{abstract}
${ }^{1}$ Mestre
Instituto de Tecnologia - IETEC. Belo Horizonte, Minas Gerais - Brasil. cqe1@hotmail.com

2 Doutor Instituto de Tecnologia - IETEC Belo Horizonte, Minas Gerais - Brasil. contato@fernandozaidan.com.br
\end{abstract}

Recebido em: 03 maio 2020

Aprovado em: 20 nov. 2020
Resumo: O objetivo principal deste estudo é elaborar o planejamento estratégico e a matriz de riscos para a Rede de Sementes do Xingu (RSX) baseados nos requisitos da NBR ISO 9001:2015 e ISO 31000:2018. O método exploratório e documental utilizado neste estudo justifica-se como o mais condizente, pois a investigação ocorreu sob uma ótica predominantemente abrangente e interpretativa, o que exigiu uma postura crítica no que tange à percepção e assimilação das várias óticas do problema central. As informações obtidas e suas relações não foram quantificáveis, entretanto, como resultado serão gerados documentos úteis para a implementação de uma rede de distribuição de sementes perene e eficaz.

Palavras-chave: Rede de sementes do Xingu. Gerenciamento de riscos. Planejamento estratégico. Reflorestamento. ISO.

Abstract: The main objective of this study is to elaborate the strategic planning and the risk matrix for the Xingu Seed Network (RSX), based on the requirements of NBR ISO 9001: 2015 and ISO 31000:2018. The exploratory and documentary method used in this study is justified as the most consistent, since the investigation took place from a predominantly comprehensive and interpretive perspective, which required a critical stance with regard to the perception and assimilation of the various perspectives of the central problem. The information obtained and its relationships were not quantifiable, however, as a result, useful documents will be generated for the implementation of a perennial and effective seed distribution network.

Keywords: Xingu seed network. Risk Management. Planning Strategic. Reforestation. ISO. 


\section{Introdução}

Os mapas e dados disponíveis para consulta na página do Instituto Nacional de Pesquisas Espaciais (INPE) permitem, desde 2004, o acesso completo a todas as informações geradas pelo sistema de monitoramento do desmatamento da floresta amazônica brasileira por satélite, o que tem possibilitado a realização de avaliações sobre as taxas de desmatamento da floresta. As estimativas geradas são consideradas confiáveis pelos cientistas nacionais e internacionais, e resultados recentes indicam nível de precisão próximo a 95\% (Kintish, 2007).

O último relatório divulgado pelo Ministério do Meio Ambiente (MMA) juntamente com o Ministério de Ciência, Tecnologia, Inovações e Comunicações (MCTIC), em 2018, revelou que as taxas de desmatamento entre agosto de 2017 e julho de 2018 haviam aumentado 13,7\% em relação aos 12 meses anteriores. Foram suprimidos $7.900 \mathrm{~km}^{2}$ da floresta amazônica, o que equivale a mais de cinco vezes a área da cidade de São Paulo. Segundo dados da World Wildlife Fund (WWF), essa é a maior taxa divulgada desde 2009, ano em que se registrou $7.464 \mathrm{~km}^{2}$ (WWF, 2018). Com a prática do desmatamento, as espécies atuais existentes na floresta amazônica têm poucas chances e tempo para desenvolver adaptações para resistir e sobreviver. Além disso, com o que se conhece hoje sobre a biologia das plantas amazônicas é possível predizer que há a possibilidade de uma extinção em massa de espécies vegetais e animais (Uhl, Da Silva, Nepstad, \& Vieira, 1991).

$\mathrm{Na}$ tentativa de estimular a coleta de sementes e ampliar a capacidade de regenaração das áreas degradadas foram estabelecidas oito redes em território nacional. Embora a maioria não tenha se mantido como unidades de negócio, no Mato Grosso, a Rede de Sementes do Xingu (RSX) tem estabelecido um sistema de gestão autossustentável.

Criada em 2007, a RSX representa uma referência na cadeia de valor florestal de base comunitária e familiar (Urzedo, 2017). Em seus 12 anos de atuação, a rede já apoiou a restauração de 5.000 hectares de áreas degradadas com a produção de 200 toneladas de sementes nativas de 220 espécies diferentes. No final de 2018 participavam da RSX cerca de 560 coletadores profissionais, entre indígenas - principalmente mulheres -, assentados, quilombolas, ruralistas e agentes urbanos, que, ao longo do rio Xingu, apresentavam-se como uma organização bem articulada e produtiva, tendo gerado mais $\mathrm{R} \$ 2,5$ milhões em renda (Urzedo, 2017).

As sementes coletadas abastecem uma técnica denominada semeadura direta, a qual se demonstra promissora no processo de recuperação ambiental (Santos, Botelho, \& Davide, 2004; Ferreira, Davide, Motta, \& Bearzoti, 2007; Ferreira et al., 2009). Além de reduzir custos, a ténica elimina toda a fase de produção de mudas em viveiro. É um procedimento barato e versátil de reflorestamento, que pode ser utilizado na maioria das condições de sítios e, principalmente, em situações onde a 
regeneração natural e, ou, os plantios de mudas não podem ser realizados com resultados satisfatórios (Barnett \& Baker, 1991; Mattei, 1995).

Diante desse contexto, o objetivo principal deste estudo é elaborar o planejamento estratégico e a matriz de riscos para a RSX baseados nos requisitos da NBR ISO 9001:2015 e ISO 31000:2018. Como resultado serão gerados documentos úteis para a implementação de uma cadeia de valor perene e eficaz, ampliando, assim, o potencial de distribuição de sementes nativas e a capacidade de estabelecimento das árvores na floresta amazônica. Além disso, a partir de um modelo de rede estruturada, a RSX poderá se apresentar como uma organização moderna e produtiva capaz de efetivar processos de negócios entre coletadores e compradores. À medida que a RSX se desenvolve, ela poderá sair de um patamar de foco em conformidade e prevenção para uma visão estratégica, que buscará oportunidades na identificação e respostas aos riscos (Collier, 2009).

Este artigo está dividido da seguinte forma: nesta introdução foram apresentados o contexto, o objetivo e a justificativa deste estudo. Em seguida serão apresentados os percursos metodológicos e o referencial teórico, o qual elucidará os conceitos utilizados para elaboração do contexto organizacional sob a ótica da NBR ISO 9001:2015 e da NBR I S O 31000:2018 e os requisitos legais para medidas compensatórias ambientais.

A partir de dados pesquisados por meio de administradores de conteúdo científico foram buscadas informações que elucidassem o funcionamento da RSX bem como a aplicação de gestão de riscos e elaboração de planejamento estratégico para o ramo de atividade da RSX. Com a finalidade de validar a elaboração do contexto organizacional e gestão estratégica de riscos a partir de dados teóricos, sem consulta in loco à organização, realizou-se a pesquisa.

\section{Referencial teórico}

Uma gestão estratégica de riscos requer uma perpectiva ampla do negócio e das estratégias. Nesse contexto, desenvolveu-se, nos anos 90, o Gerenciamento de Riscos Corporativos (GRC), o qual ganhou força nos anos 2000, principalmente devido à crise global iniciada em 2008 (Wu \& Olson, 2010).

O interesse no gerenciamento de riscos tem crescido continuamente, fortalecido pela disseminação de modelos internacionais (Carneiro, Costa, Gilberto \& Tomas, 2019), e pesquisas recentes abordam a disseminação de modelos de adoção voluntária, que definem e regulam atividades, a exemplo das normas da ISO e do modelo Comittee of Sponsoring Organizations Enterprise Risk Management - COSO ERM (Hayne \& Free, 2014).

Sabe-se que o desempenho da cadeia de suprimentos depende da coordenação entre atores e exige que cada componente da cadeia leve em conta os efeitos de sua ações em outros componentes (Chopra \& Meindl, 2013). Nesse sentido, entender os principais conceitos relacionados ao 
gerenciamento de riscos em cadeias de suprimentos poderia auxiliar na elaboração da matriz de riscos para a RSX.

\subsection{Processo de gestão de risco NBR ISO 31000:2018}

A NBR ISO 31000:2018 apresenta os princípios gerais sobre gerenciamento de risco e é resultado da discussão de grupo de trabalho estabelecido com a participação especialistas nomeados e representantes de diferentes organizações de 28 países. A ISO atualizou a Standards Australian and Standards New Zealand (AS/NZS) 4360:2004 abordando nova definição de riscos e estabeleceu 11 princípios. Desde de 2009, esta é recomendada como guia para gerenciamento de risco e teve sua nova versão publicada em 28 de março de 2018 (Olechowski, Oehmen, Seering \& Ben-Daya, 2016).

Themsen e Skærbæk (2018), em sua revisão sistemática, abordam que a ISO é a referência mais utilizada nas últimas três décadas por diferentes áreas, setores públicos e privados. Essa norma pode ser aplicada em qualquer ciclo de vida da organização e em uma ampla variedade de atividades, incluindo estratégias, operacionais, processos, funções, projetos, produtos, serviços e em quaisquer tipos de riscos, quer apresentem consequências positivas ou negativas (Thekdi \& Aven, 2016; Abnt, 2015).

Gerenciar riscos se baseia, segunda a norma ISO 31001, nos princípios estrutura e processos, como ilustrado na Figura 1. Para elaboração da matriz de risco para a RSX serão utilizados os conceitos do processo de avaliação de risco e de tratamento do risco. 
Figura 1

Gerenciamento de riscos: princípios, estrura e processo

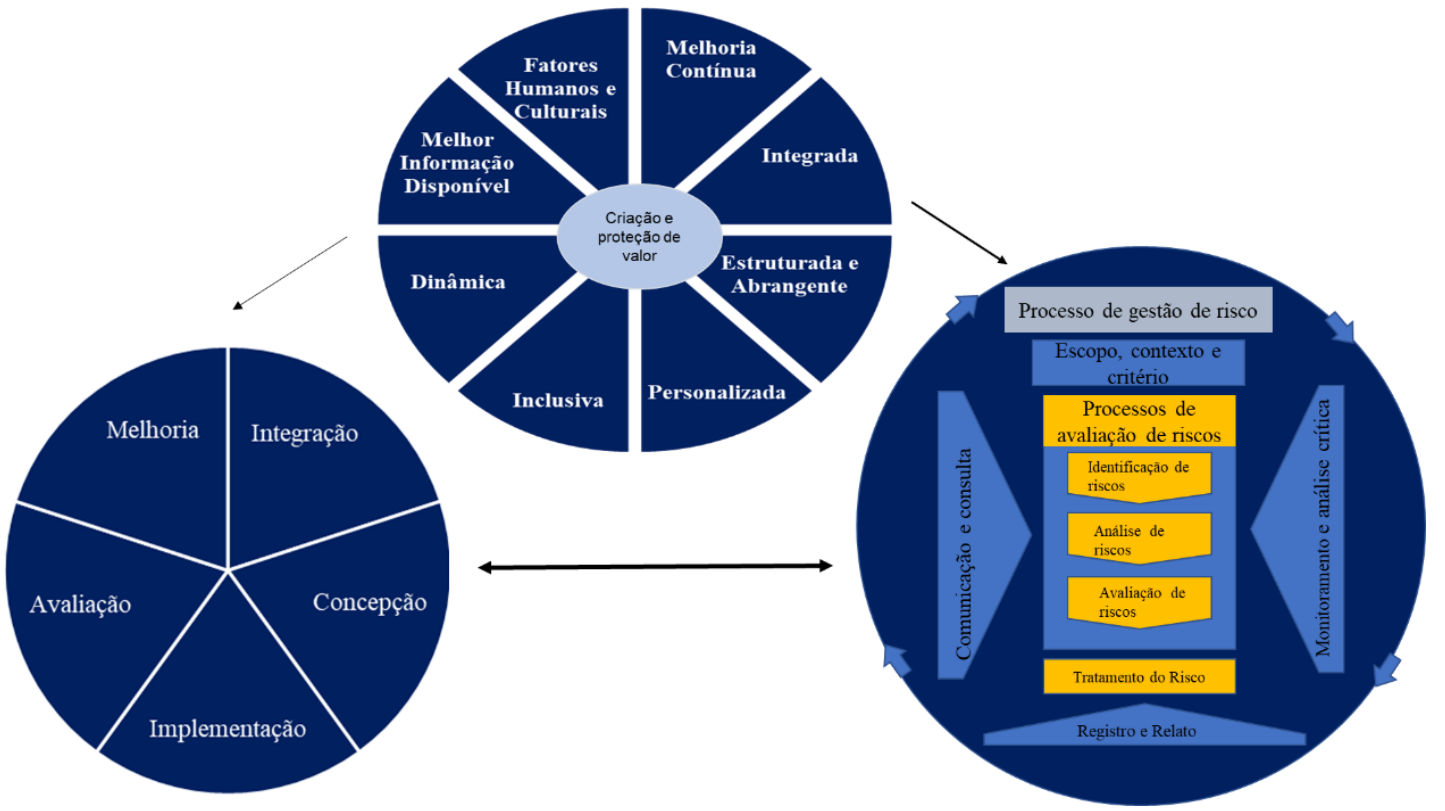

Fonte: Adaptado de Abnt (2015).

A etapa de identificação de riscos associa os dados levantados no estabelecimento do contexto com as possíveis fontes de riscos, as áreas que podem ter algum impacto e os eventos que podem ocorrer. A análise verifica as fontes, causas, consequências, probabilidade de ocorrências, bem como os níveis de riscos.

$\mathrm{Na}$ fase de avaliação de riscos, os impactos reais são medidos e considerados. Essa etapa também descreve as melhores estratégias e métodos a serem implementados para a fase de tratamento de riscos. Os riscos podem ser avaliados em nível organizacional, em nível departamental, sejam por projetos, atividades individuais ou específicas (Salgado et al., 2019).

A Norma ISO GUIDE 73:2009 é uma adoção idêntica da norma que foi elaborada pelo ISO Technicat Management Board Working Group on Risk Management e define que o risco, muitas vezes, é expresso em termos de uma combinação de consequências de um evento e a probabilidade de ocorrência associada. Esse conceito de probabiliade pode ser compreendido como a chance de algo acontecer, não importando se objetiva ou subjetivamente ou se descrita utilizando-se termos gerais ou matemáticos.

\subsection{Gerenciamento de riscos em cadeias de suprimentos}

A primeria produção bibliométrica sobre gestão de riscos em cadeias de suprimentos no Brasil foi apresentada em 2017 em um artigo entitulado "A produção acadêmica internacional sobre gestão de risco na cadeia de suprimentos no período entre 2005 e 2014", de autoria de Matos, Vitorino, Spers 
e Pires. A pesquisa trata risco na cadeia de suprimentos e define o mesmo como a possibilidade de haver desbalanceamento entre demanda e suprimentos e seus efeitos que criam interrupções na cadeia (Tang \& Musa, 2011).

Para Jüttner, Peck e Christopher (2003), os riscos na cadeia de suprimentos compreendem os riscos para os fluxos de informação, materiais e produtos, desde o fornecedor inicial até o usuário final do produto.

Christopher e Lee (2004) definem a gestão de risco em cadeias de suprimentos como a gestão dos riscos por meio de uma abordagem coordenada entre os membros da cadeia de suprimentos para reduzir a vulnerabilidade da cadeia como um todo.

Mediante os inúmeros modelos de gestão de risco para a cadeia de suprimentos identificados por Tomas e Alcantara (2013), as organizações devem analisar a sua cadeia e então desenvolverem um modelo de gestão eficaz nesse sentido. Entretanto, independentemente do modelo, Kern, Moser, Hartmann e Moder (2012) propõem que as estruturas devem sempre possuir em suas etapas a fase de mitigação dos riscos. Existem diferentes estratégias para essa fase, Manuj e Mentzer (2008) apresentam diferentes estratégias para mitigação dos riscos, dentre elas: limitar o número de fornecedores, controlar, compartilhar e transferir.

\subsection{Os requitos de direcionamento estratégico da norma ISO 9001:2015}

A Organização Internacional para Padronização (ISO), desde 1987, quando foi publicada a primeira versão da ISO 9001 - Requisitos para Sistemas de Gestão da Qualidade, promove revisões no texto das normas de forma a mantê-lo alinhado com conceitos de gestão modernos, perenes e eficazes. Nesse sentido, a norma ISO 9001:2015 foi definida como base teórica para desenvolvimento do contexto organizacional alinhada com os requisitos de gestão de riscos definidos na norma ISO 31000:2018.

A NBR ISO 9001:2015 estabelece:

[...] ao planejar o sistema de gestão da qualidade, a organização deve considerar as questões referidas em 4.1 (Entendendo a Organização e seu Contexto) e em 4.2 (Entendendo as necessidades e expectativas das partes interessadas e determinar riscos e oportunidades que precisem ser abordados para: assegurar que o sistema de gestão da qualidade possa alcançar seus resultados pretendidos; aumentar efeitos desejáveis; prevenir, ou reduzir, efeitos indesejáveis; alcançar a melhoria (Abnt, 2015, p. 5).

No contexto da ISO 9001: 2015 deve-se definir o propósito da empresa e seu direcionamento estratégico a partir da análise de ambiente interno e externo. Nesse sentido, o modelo mais adequado de planos estratégicos e ferramenta para análise de ambiente deve ser definido no âmbito da organização. 
$\mathrm{Na}$ literatura são encontradas um série de proposições e, de acordo com Besanko, Dranove e Shanley (2000), deve-se evitar frases comuns como "metas e políticas de longo prazo", o que poderia sugerir que estratégias estão relacionadas a uma sequência de ações que levariam às organizações a sucessos e, ou, fracassos.

\subsection{Desdobramento da função da qualidade}

O desdobramento da função da qualidade - QFD teve sua caracterização definida em 1972 no Japão. Esse método pode ser aplicado tanto para produto ou serviços e possui duas finalidades básicas: auxiliar no desenvolvimento do produto e garantir qualidade durante o desenvolvimento (Cheng et al., 1995).

O método é também conhecido como matriz da qualidade, e é uma sistematização das qualidades exigidas pelos clientes que expressa a relação entre as funções e as características da qualidade (Akao, 1996).

Para aplicação neste estudo considerou-se a execução da revisão sistemática de literatura como um produto a ser desenvolvido. Nesse sentido, utilizou-se os conceitos básicos de QFD para ordenação dos requisitos mais importantes na formação das correlações das strings utilizadas na elaboração da RSL e, assim, atingir os objetivos desejados no desenvolvimento.

\subsection{Desmatamento e medidas compensatórias legais}

Em decorrência do modelo de reforma agrária na Amazônia Legal, a demografia da região amazônica é fortemente influenciada por um grande fluxo migratório. Com menos de $15 \%$ da população rural do país, ela abriga quase $55 \%$ dos lotes distribuídos pelo Instituto Nacional de Colonização e Reforma Agrária (INCRA) (Le Tourneau \& Bursztyn, 2010).

Considerando que, tradicionalmente, a conversão do habitat nativo em usos alternativos tem sido a forma de apropriação do território brasileiro, esse modelo tende a reforçar o desmatamento e a degradação ambiental na região, mesmo diante do vasto amparo legislativo. Nesse sentido, os requisitos compensatórios, como o instituto de proteção ambiental, foram expressamente previstos no texto da Convenção sobre Diversidade Biológica, aprovado pelo Congresso Nacional, por meio do Decreto Legislativo 02/1994 (Faria, 2008).

A resolução 10/1987 do Conselho Nacional do Meio Ambiente (Conama) inseriu, originariamente, no ordenamento jurídico brasileiro, a compensação para os empreendimentos causadores de significativo impacto ambiental, tendo sido modificada pela resolução Conama 02/1996, que, posteriormente, foi substituída por lei específica. 
Uma compilação da legislação ambiental brasileira, apresentada a seguir, publicada pelo Ministério do Meio Ambiente, em 2008, visa, em linhas gerais, englobar:

[...] aspectos no que diz respeito à Política Nacional do Meio Ambiente, flora e fauna, águas, educação ambiental, crimes e infrações administrativas ambientais, bem como unidades de conservação, patrimônio genético, proteção e acesso ao conhecimento tradicional associado, repartição de benefícios e ainda organismos geneticamente modificados (Brasil, 2008, p. 9).

A Lei n. 9.985/00, que institui o Sistema Nacional de Unidades de Conservação da Natureza, determina a obrigatoriedade do pagamento, pelo empreendedor, de, pelo menos, 0,5\% do valor total do empreendimento em caso de significativo impacto ambiental. A fundamentação dessa exigência legal pauta-se nos estudos ambientais realizados no processo de licenciamento ambiental, estudo de impacto ambiental (EIA) e relatório de impacto ambiental (RIMA) (BRASIL, 2000).

A Lei n. 12.651/12 regula o uso e a recuperação de áreas protegidas e estabelece normas gerais sobre a proteção da vegetação, áreas de preservação permanente e as áreas de reserva legal; a exploração florestal, o suprimento de matéria-prima florestal, o controle da origem dos produtos florestais e o controle e prevenção dos incêndios florestais, e prevê instrumentos econômicos e financeiros para o alcance de seus objetivos (BRASIL, 2012).

A Lei n. 6.938/81 estabelece a Política Nacional do Meio Ambiente e tem por objetivo a preservação, melhoria e recuperação da qualidade ambiental propícia à vida, visando assegurar, no país, condições ao desenvolvimento socioeconômico aos interesses da segurança nacional e à proteção da dignidade da vida humana (BRASIL, 1981).

A Lei n. 6.905/98 estabelece punições para aqueles que desmatam sem autorização, propondo os termos de ajustamento de conduta para minimização do dano (BRASIL, 1998).

Bechara (2007, p. 190) afirma que o objetivo da compensação ambiental é, a grosso modo, "compensar uma perda inevitável com um ganho ambiental desejável. Assim, a atividade que afeta o equilíbrio ambiental, em uma ponta, melhora sua condição em outra". Nesse sentido, os recursos destinados à compensação ambiental podem ser remanejados para outras destinações, conforme a ordem de prioridade elencada no Decreto Federal 4.340/2002.

Entretanto, a dimensão ambiental estabelecida por Sachs (2009, p. 86) descreve que se deve "respeitar e realçar a capacidade de autodepuração dos ecossistemas naturais". A autodepuração é a capacidade que o meio ambiente natural possui de recompor suas características naturais, sem a intervenção humana.

Mesmo que a compensação ambiental institua a obrigação de restauração de ecossistemas afetados ou reflorestamento, a reparação dessas áreas nunca será plena. Nesse sentido, Lopes e Gomes (2017, p. 121) afirmam que a compensação ambiental deve "priorizar sempre a reparação in natura dos ecossistemas afetados, recompondo suas características naturais, a fauna e a flora". 
Assim, percebe-se a necessidade de se ampliarem as redes de sementes, garantindo, dessa forma, a perenidade destas e a possibilidade de fornecimento de matéria-prima em quantidade e qualidade suficientes para apoiar as medidas de compensção ambiental.

\section{Metodologia}

A metodologia utilizada é do tipo qualitativa, exploratória e bibliográfica. Quanto à abordagem qualitativa, esta ocorreu sob uma ótica predominantemente abrangente e interpretativa, o que exigiu uma postura crítica no que tange à percepção e assimilação das várias óticas do problema central.

Por não serem quantificáveis, os resultados da pesquisa qualitativa, a condução do processo de investigação científica deve circunscrever o caráter subjetivo do objeto analisado, estudando-se as suas particularidades e experiências individuais (Gil, 2017).

Easterby-Smity, Thorpe e Lowe (1999) apontam que são necessários procedimentos de pesquisa que atendam ao problema levantado e aos seus propósitos e, conforme Saunders, Lewis e Thornill (2012), a resposta ao problema pode ser dada pela compreensão dos fatos, de forma que a preocupação do pesquisador está no contexto em que os eventos acontecem.

Em pesquisas exploratórias, o estudo de caso, conforme Yin (2005), também se apresenta especialmente importante, uma vez que o caso a relatar aproxima o pesquisador do tema da questão central.

Para revisão sistemática de literatura aplicou-se o protocolo RepOrting Standards for Systematic Evidence Syntheses (ROSES), cuja função é identificar e classificar qualitativamente os métodos de elaboração de um planejamento estratégico e gestão de riscos com abordagem empresarial, notamente baseadas nas normas ISO 9001:2015 e ISO 31000:2018. Esse protocolo foi definido, uma vez que ele permite aos pesquisadores uma garantia de que todas as informações metodológicas relevantes sejam relatadas em sua revisão.

Aplicou-se, também, um questionário para suporte à hipótese de elaboração do contexto organizacional por meio de informações documentais. Segundo Aaker, Kumar e Day (2001), a elaboração de um questionário é considerada uma arte imperfeita, pois não existem procedimentos exatos que garantam que os objetivos de medição sejam alcançados com boa qualidade. Entretanto, existe uma sequência de etapas lógicas que o pesquisador deve seguir para desenvolver um questionário: planejar o que vai ser mensurado; formular as perguntas para obter as informações necessárias; definir o texto e a ordem das perguntas e o aspecto visual do questionário; testar o questionário em relação a omissões e ambiguidade utilizando uma pequena amostra; caso necessário, corrigir o problema e fazer novo pré-teste (Aaker, Kumar \& Day, 2001). 
Isto posto, a abordagem metodológica deste artigo baseou-se em um estudo de caso, uma revisão sistemática de literatura (RSL) e a aplicação de um questionário. A partir do estudo de caso identificaram-se informações consistentes sobre etapas, processos e autores relacionados à RSX.

\section{Revisão sistemática de literatura}

Uma série de terminologias e interpretações sobre riscos e estratégias é encontrada hoje na literatura, algumas delas sem uma contextualização técnica ou científica. O protocolo ROSES desenvolveu-se da seguinte forma:

\subsection{Definição do objetivo}

Identificar e classificar qualitativamente os métodos de elaboração de um planejamento estratégico e gestão de riscos com abordagem empresarial baseados nas normas ISO 9001:2015 e ISO 31000:2018.

\subsection{Definição da questão primária}

a) Quais são os métodos de planejamento estratégico e gestão de riscos utilizados por empresas que comercializam sementes?

\subsection{Definição da questão secundária}

a) É possível afirmar que a aplicação dessas técnicas aumentou a perenidade das unidades de negócio que comercializam sementes nativas?

\subsection{Estratégias da pesquisa}

Visando ampliar a capacidade de análise para os componentes da pergunta foram utilizados os parâmetros estabelecidos de acordo com o modelo de análise do diagrama de causa e efeito para elaboração do diagrama de causa e efeito. Assim, a definição das palavras-chave e temas de busca é baseada nas categorias do diagrama, permitindo ao pesquisador associar sua busca a seis áreas, definidas da seguinte maneira:

1) Mão de obra: listar os cargos correlacionados com as atividades laborais envolvidas nas questões primária e secundária. Nos critérios de busca devem ser relacionadas as áreas de atuação;

2) Matéria-prima: definir o produto final ou matéria-prima; 
3) Método: elencar os nomes das atividades ou processos envolvidos;

4) Ambiente: descrever os locais onde a trabalho é realizado;

5) Medição: estabelecer dados possíveis de serem mensurados;

6) Máquina: equipamentos de infraestrutura relativos aos métodos, não aplicável para o objetivo de busca desta RSL.

Ao estabelecer os componentes da pesquisa e antes de se iniciarem as buscas, estabeleceu-se o grau de correlação entre os elementos da matriz. A análise de correlação baseou-se na teoria das correlações para montagem da matriz do Desdobramento da Função da Qualidade [QFD]. Os graus de intensidade são atribuidos para o cruzamento entre os pares de elementos descritos na coluna x linha.

A definição dos parâmetros de busca, deu-se da seguinte forma:o administrador de conteúdo escolhido foi o EBSCO; o tipo de busca foi avançado/ texto completo; o modo de busca foi por booleano/frase; o período estabelecido foi de julho de 2015 a novembro de 2019; o tipo de documento selecionado foi artigo científico, em língua portuguesa e sem palavras equivalentes.

Como gerenciador da bibliografia utilizou-se o State of the Art through Systematic Review (StArt). O StArt é uma ferramenta gratuita desenvolvida no laboratório de pesquisa em engenharia de software da Universidade Federal de São Carlos. A ferramenta está dividia em planning, que compreende o protocolo; execution, etapa que armazena o título e resumo de cada trabalho pesquisado por par das categorias, de acordo com a classificação de cada artigo; o summarization, onde é possivel descrever a forma de extração e a síntese qualitativa dos artigos selecionados.

\subsection{Sintese qualitativa}

A leitura para classificação dos artigos, como aceitos e sumarizados ou rejeitados e não sumarizados, baseou-se na correlação do Quadro 1, ou seja, artigos encontrados a partir das categorias classificadas como $A C$ = alta correlação leitura completa; $M C=$ média correlação leitura da introdução e resultados; $B C$ = baixa correlação leitura do resumo; $V C$ = vaga correlação leitura do título. 


\section{Quadro 1}

Matriz de strings, grau de correlação e quantidades de estudos encontrados

\begin{tabular}{|c|c|c|c|c|c|c|c|c|c|c|c|c|c|}
\hline \multicolumn{14}{|c|}{ ESTILO DE BUSCA BOOLENA COM UTLLIZAÇÃO DO 'AND' PARA OS TERMOS DA (LINHA X COLUNA): } \\
\hline \multirow{2}{*}{ CATEGORIAS } & \multirow{2}{*}{\begin{tabular}{|c|} 
QUESTÃO PRIMARIA \\
ELEMENTOS DAS CATEGORIAS
\end{tabular}} & \multicolumn{5}{|c|}{ de Risco e Planejamento Estratégico } & \multicolumn{6}{|c|}{ sob a abordagem ISO 9001:2015 para o negócio de } & \multirow{2}{*}{$\begin{array}{c}\text { sementes r } \\
5.3 \\
\text { REF }\end{array}$} \\
\hline & & $\begin{array}{c}1.1 \\
\text { CON }\end{array}$ & $\begin{array}{l}1.2 \\
\text { COL }\end{array}$ & $\begin{array}{l}2.0 \\
\text { SEN }\end{array}$ & $\begin{array}{c}3.1 \\
\text { GER }\end{array}$ & $\begin{array}{l}3.2 \\
\text { PLE }\end{array}$ & $\begin{array}{r}\mathbf{3 . 3} \\
\text { RES }\end{array}$ & $\begin{array}{c}3.4 \\
9001\end{array}$ & $\begin{array}{c}3.5 \\
31000\end{array}$ & $\begin{array}{r}4.1 \\
\text { FOA }\end{array}$ & $\begin{array}{c}5.1 \\
\text { PSN }\end{array}$ & $\begin{array}{l}5.2 \\
\text { DEI }\end{array}$ & \\
\hline \multirow{2}{*}{ MÃO DE OBRA } & 1.1 Consultores (CON) & $\begin{array}{l}\text { vc } \\
50\end{array}$ & $\begin{array}{c}\text { BC } \\
0\end{array}$ & $\begin{array}{c}\text { MC } \\
0\end{array}$ & $\begin{array}{c}\mathbf{A C} \\
0\end{array}$ & $\begin{array}{c}\text { AC } \\
0\end{array}$ & $\begin{array}{c}\text { BC } \\
0\end{array}$ & $\begin{array}{c}\text { AC } \\
0\end{array}$ & $\begin{array}{c}\text { AC } \\
0\end{array}$ & $\begin{array}{c}\text { BC } \\
0\end{array}$ & $\begin{array}{c}\text { BC } \\
0\end{array}$ & $\begin{array}{c}\text { BC } \\
0\end{array}$ & $\begin{array}{c}\text { BC } \\
\mathbf{0}\end{array}$ \\
\hline & 1.2 Coletores (COL) & & $\begin{array}{c}\text { vc } \\
0\end{array}$ & $\begin{array}{c}\text { BC } \\
\text { O }\end{array}$ & $\begin{array}{c}\text { BC } \\
0\end{array}$ & $\begin{array}{c}\text { BC } \\
0\end{array}$ & $\begin{array}{c}\text { BC } \\
0\end{array}$ & $\begin{array}{c}\text { MC } \\
0\end{array}$ & $\begin{array}{c}\text { MC } \\
0\end{array}$ & $\begin{array}{c}\text { BC } \\
0\end{array}$ & $\begin{array}{c}\mathbf{A C} \\
0\end{array}$ & $\begin{array}{c}\text { MC } \\
0\end{array}$ & $\begin{array}{c}\text { MC } \\
0\end{array}$ \\
\hline MATÉRIA PRIMA & 2.0 Sementes Nativas (SEN) & & & $\begin{array}{c}\text { vc } \\
0\end{array}$ & $\begin{array}{c}A C \\
0\end{array}$ & $\begin{array}{c}A C \\
0\end{array}$ & $\begin{array}{c}A C \\
0\end{array}$ & $\begin{array}{c}A C \\
0\end{array}$ & $\begin{array}{c}A C \\
0\end{array}$ & $\begin{array}{c}\text { MC } \\
0\end{array}$ & $\begin{array}{c}\text { MC } \\
\text { O }\end{array}$ & $\begin{array}{c}\text { MC } \\
0\end{array}$ & $\begin{array}{c}\text { MC } \\
0\end{array}$ \\
\hline \multirow{5}{*}{ MÉTOdO } & 3.1 Gestão de Risco (GER) & & & & $\begin{array}{l}\text { MC } \\
67\end{array}$ & $\begin{array}{c}A C \\
1\end{array}$ & $\begin{array}{c}\mathbf{A C} \\
0\end{array}$ & $\begin{array}{c}\mathbf{A C} \\
0\end{array}$ & $\begin{array}{c}\mathbf{A C} \\
0\end{array}$ & $\begin{array}{c}\text { AC } \\
0\end{array}$ & $\begin{array}{c}\mathbf{A C} \\
0\end{array}$ & $\begin{array}{c}\mathbf{A C} \\
0\end{array}$ & $\begin{array}{c}A C \\
0\end{array}$ \\
\hline & $\begin{array}{l}\text { 3.2 Planejamento Estratégico } \\
\text { (PLE) }\end{array}$ & & & & & $\begin{array}{l}\text { MC } \\
87\end{array}$ & $\begin{array}{c}\mathbf{A C} \\
\mathbf{0}\end{array}$ & $\begin{array}{c}\mathbf{A C} \\
\mathbf{0}\end{array}$ & $\begin{array}{c}\mathbf{A C} \\
\mathbf{0}\end{array}$ & $\begin{array}{c}\mathbf{A C} \\
\mathbf{0}\end{array}$ & $\begin{array}{c}\mathbf{A C} \\
\mathbf{0}\end{array}$ & $\begin{array}{c}\mathbf{A C} \\
\mathbf{0}\end{array}$ & $\begin{array}{c}\mathbf{A C} \\
\mathbf{0}\end{array}$ \\
\hline & 3.3 Rede Sementes (RES) & & & & & & $\begin{array}{c}\text { vc } \\
\mathbf{0}\end{array}$ & $\begin{array}{c}\mathbf{A C} \\
\mathbf{0}\end{array}$ & $\begin{array}{c}\mathbf{A C} \\
\mathbf{0}\end{array}$ & $\begin{array}{c}\text { MC } \\
\mathbf{O}\end{array}$ & $\begin{array}{c}\text { MC } \\
\mathbf{O}\end{array}$ & $\begin{array}{c}\text { MC } \\
0\end{array}$ & $\begin{array}{c}\text { MC } \\
\mathbf{O}\end{array}$ \\
\hline & 3.4 I $\$ 0$ 9001:2015 & & & & & & & $\begin{array}{c}\text { AC } \\
1\end{array}$ & $\begin{array}{c}\mathbf{A C} \\
\mathbf{0}\end{array}$ & $\begin{array}{c}\text { MC } \\
\mathbf{0}\end{array}$ & $\begin{array}{c}\text { MC } \\
\text { O }\end{array}$ & $\begin{array}{c}\mathrm{MC} \\
1\end{array}$ & $\begin{array}{c}\text { MC } \\
\text { O }\end{array}$ \\
\hline & 3.5 I S O 31000:2018 & & & & & & & & $\begin{array}{c}\mathbf{A C} \\
\mathbf{0}\end{array}$ & $\begin{array}{c}\mathbf{A C} \\
\mathbf{0}\end{array}$ & $\begin{array}{c}\mathbf{A C} \\
\mathbf{0}\end{array}$ & $\begin{array}{c}\mathbf{A C} \\
\mathbf{0}\end{array}$ & $\begin{array}{c}\mathbf{A C} \\
\mathbf{0}\end{array}$ \\
\hline AMBIENTE & 4.1 Floresta Amazônica & & & & & & & & & $\begin{array}{l}\text { vc } \\
12\end{array}$ & $\begin{array}{c}\text { BC } \\
\mathbf{O}\end{array}$ & $\begin{array}{c}\text { BC } \\
\mathbf{O}\end{array}$ & $\begin{array}{c}\text { vc } \\
1\end{array}$ \\
\hline \multirow{3}{*}{ MEDIÇÃo } & $\begin{array}{l}\text { 5.1 Produçäo de Sementes } \\
\text { Nativas (PSN) }\end{array}$ & & & & & & & & & & $\begin{array}{c}\text { vc } \\
6\end{array}$ & $\begin{array}{c}\text { vc } \\
\mathbf{0}\end{array}$ & $\begin{array}{c}\text { vc } \\
3\end{array}$ \\
\hline & 5.2 Desmatamento Ilegal (DEI) & & & & & & & & & & & $\begin{array}{c}\text { vc } \\
1\end{array}$ & $\begin{array}{c}\text { vc } \\
\mathbf{0}\end{array}$ \\
\hline & 5.3 Reflorestamento (REF) & & & & & & & & & & & & $\begin{array}{c}\text { vc } \\
1\end{array}$ \\
\hline
\end{tabular}

Fonte: Da autora, 2020.

De acordo com o exposto, ao executar a leitura para aceitação ou rejeição dos artigos na fase de extração foram utilizados cinco questionamentos:

1) O texto ou título estabelece metodologia para análise de ambiente organizacional?

2) Menciona análise de ambiente interno e externo para elaboração do planejamento estretágico?

3) Menciona gestão de riscos sobre processos, mudanças e estratégias?

4) Menciona a análise de oportunidades como uma forma de gerir riscos?

5) Apresenta modelo para estabelecer prioridades de ações relacionadas aos riscos?

Artigos com temática relacionada à gestão de riscos ambientais, riscos à saúde pública, turismo, financeiro ou segurança do trabalho, bem como estratégias para melhoria da qualidade de vida da sociedade foram excluídos e não foram sumarizados. Na etapa de sumarização utililizou-se um score de 1 a 5 para conclusão dos resultados da pesquisa. Dessa forma, os artigos de alta correlação passaram por uma releitura e artigos que tiveram a correlação alterada foram lidos integralmente. Artigos com score 0 não foram sumarizados. A cada pergunta respondida de forma afirmativa um ponto foi associado. 


\subsection{Análise dos resultados}

A definição das strings, a partir das categorias estabelecidas, permitiu uma abrangência de 144 possibilidades, conforme Quadro 1; destas, 134 retornaram com resultado 0, ou seja, nenhum estudo foi encontrado. No sentido oposto, foram identificados 279 artigos por meio de 10 strings. A análise do potencial de eficácia dos artigos encontrados pode ser verificada, uma vez que ao aplicar "keyword analysis", da ferramenta stArt, obteve-se a nuvem representada na Figura 2. Isso representa que a busca está alinhada com o objetivo da RSL, ou seja, identificar quais os métodos de planejamento estratégico e gestão de riscos utilizados por empresas que comercializam sementes.

\section{Figura 2}

Nuvem de palavras-chave dos artigos pesquisados

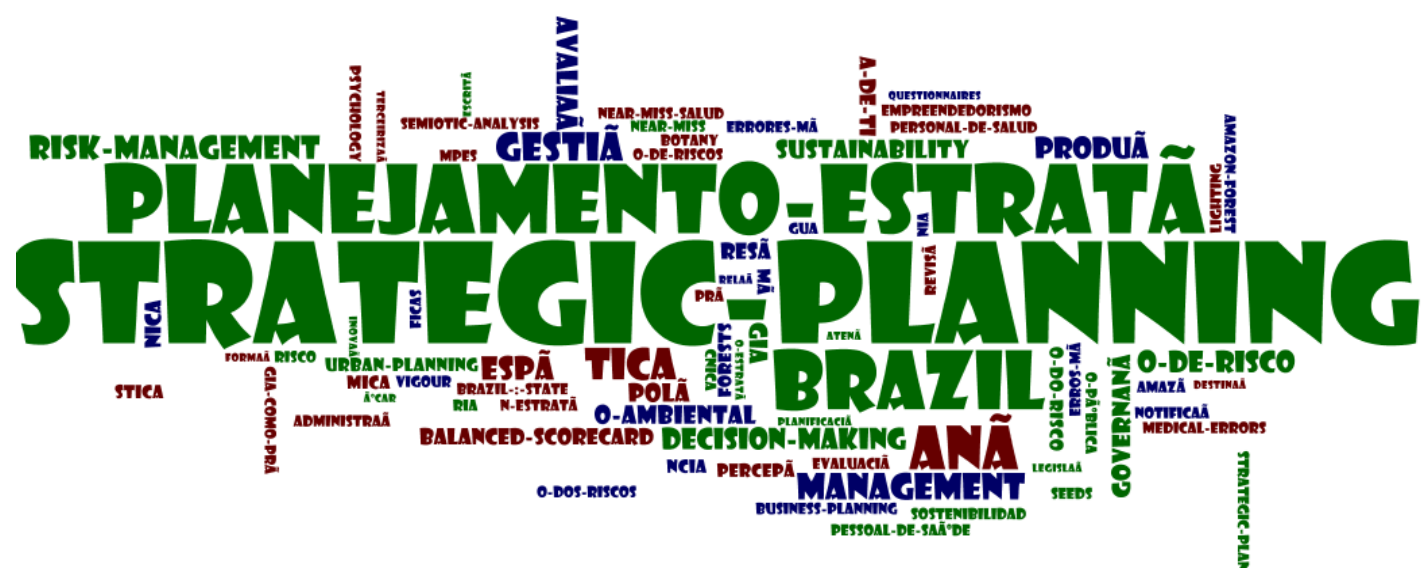

Fonte: Da autora, 2020

As leituras foram efetuadas de acordo com os critérios já mencionados. Assim, a maior parte das rejeições se deu pelo fato de os artigos estarem relacionados à gestão de riscos ambientais, riscos à saúde pública, turismo, financeiro ou segurança do trabalho, bem como estratégias para melhoria da qualidade de vida da sociedade. Entretanto, 11 artigos foram extraídos e, após a leitura completa dos textos, foi obtido o resultado da Quadro 2, que apresenta seis artigos selecionados. 


\section{Quadro 2}

Sintese do resultado da RSL

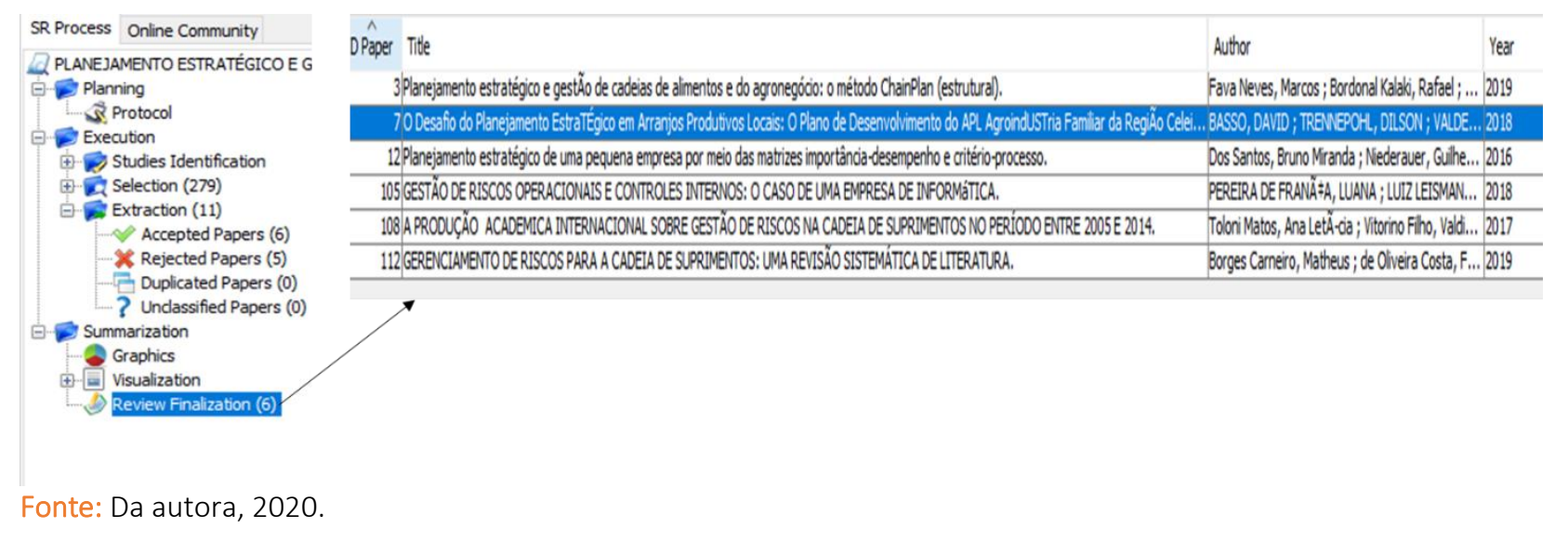

A partir desses resultados não foi possível estabelecer, com elevada efetividade, que a ISO 31000 é uma norma efetiva para análise de riscos e que a análise de ambientes interno e externo é uma etapa para desenvolvimento do planejamento estratégico.

Apesar do método rigoroso para revisão bibliográfica, a mesma demonstrou pouca efetividade. Isso pode estar relacionado ao fato de que a gestão de riscos é uma abordagem recente no ambiente de cadeias de suprimentos (Aguiar, 2010).

Outro parâmetro que deve ser considerado é que as inovações gerenciais, como a gestão de riscos, mesmo tendo sua adoção intensificada nos últimos 20 anos, sobretudo em relação aos modelos COSO ERM e ISO 31000:2009, encontra entraves à sua expansão (Huber \& Scheytt, 2013; Scheytt, Soin, Sahlin-Andersson, \& Power, 2006). Essa prática tem sido limitada pela necessidade de adequação da inovação ao contexto local, o que levaria a maiores dificuldades para sua implementação, dadas as diferenças de recursos materiais e de conhecimento ou devido a diferenças culturais específicas (PerezAleman, 2010).

Por fim, cabe destacar que a gestão de riscos é uma abordagem recente no ambiente de cadeias de suprimentos (Aguiar, 2010). Jüttner et al. (2003) afirmam que apesar da crescente conscientização entre os profissionais, os conceitos de vulnerabilidade e gestão de riscos nas cadeias de suprimentos ainda estão na infância.

Tomas e Alcantara (2013) afirmam que parte significativa das pesquisas foram desenvolvidas em não mais de 12 anos, devido, em grande parte, a uma série de tendências como globalização, terceirização, a transição para operações enxutas e ágeis, ataques terroristas, e outras ameaças. 


\section{Estudo de caso}

\subsection{Seleção de conteúdo sobre a RSX}

A seleção de conteúdo científico sobre a cadeia de valor da Rede de Sementes do Xingu foi realizada por meio da busca em acervos disponibilizados pelos administradores SCiELO, Ebsco, OasisBR e Google Acadêmico. Foram aplicados modos de busca avançada para o período compreendido entre 2009 (ano de criação da RSX) e abril de 2019. Após dois meses de análises nesses acervos, entre março e abril de 2019, foram encontradas informações relevantes sobre a RSX, suficientes para estabelecer informações para o estudo de caso sobre a RSX. No Quadro 3 é apresentado o modo de pesquisa que gerou o resultado das duas teses de doutorado que tratavam sobre o tema Rede de Sementes do Xingu, dos autores Sanches (2015) e Urzedo (2014).

\section{Quadro 3}

Seleção de artigos, teses e dissertações que versam sobre RSX

\begin{tabular}{ll|lll} 
Administrador & \multicolumn{1}{c}{ Modo de Pesquisa } & \multicolumn{1}{c}{$\begin{array}{c}\text { Quantidade } \\
\text { encontrada }\end{array}$} & $\begin{array}{l}\text { Quantidade } \\
\text { Selecionada }\end{array}$ \\
EBSCO & Pesquisa aberta com a palavra "Xingu" & 893 & 2 & \\
EBSCO & Pesquisa aberta "Xingu sementes" & 893 & 2 & 2 \\
EBSCO & Pesquisa aberta "Xingu seeds" & 39 & 2 & 2 \\
EBSCO & $\begin{array}{l}\text { Pesquisa com filtro somente texto } \\
\text { completo “Xingu sementes" }\end{array}$ & 2 & &
\end{tabular}

Fonte: Da autora, 2020

Nota: Filtro 2007 a 2019 (data de início da busca - 19 de maio de 2019; data de conclusão da busca - 12 de junho de 2019).

\subsection{Apresentação do resultado}

\subsubsection{O Sistema funcional da cadeia de valor da RSX na Amazônia brasileira}

O sistema funcional da cadeia de valor da Rede de Sementes do Xingu é composto principalmente por uma complexa logística de armazenamento e distribuição utilizada para a comercialização das diferentes espécies de sementes, ou seja, um elaborado sistema de gestão, o qual integra os processos descritos na Figura 3. 


\section{Figura 3}

Sistema funcional da cadeia de valor da RSX na Amazônia brasileira abrangendo etapas, processos e atores

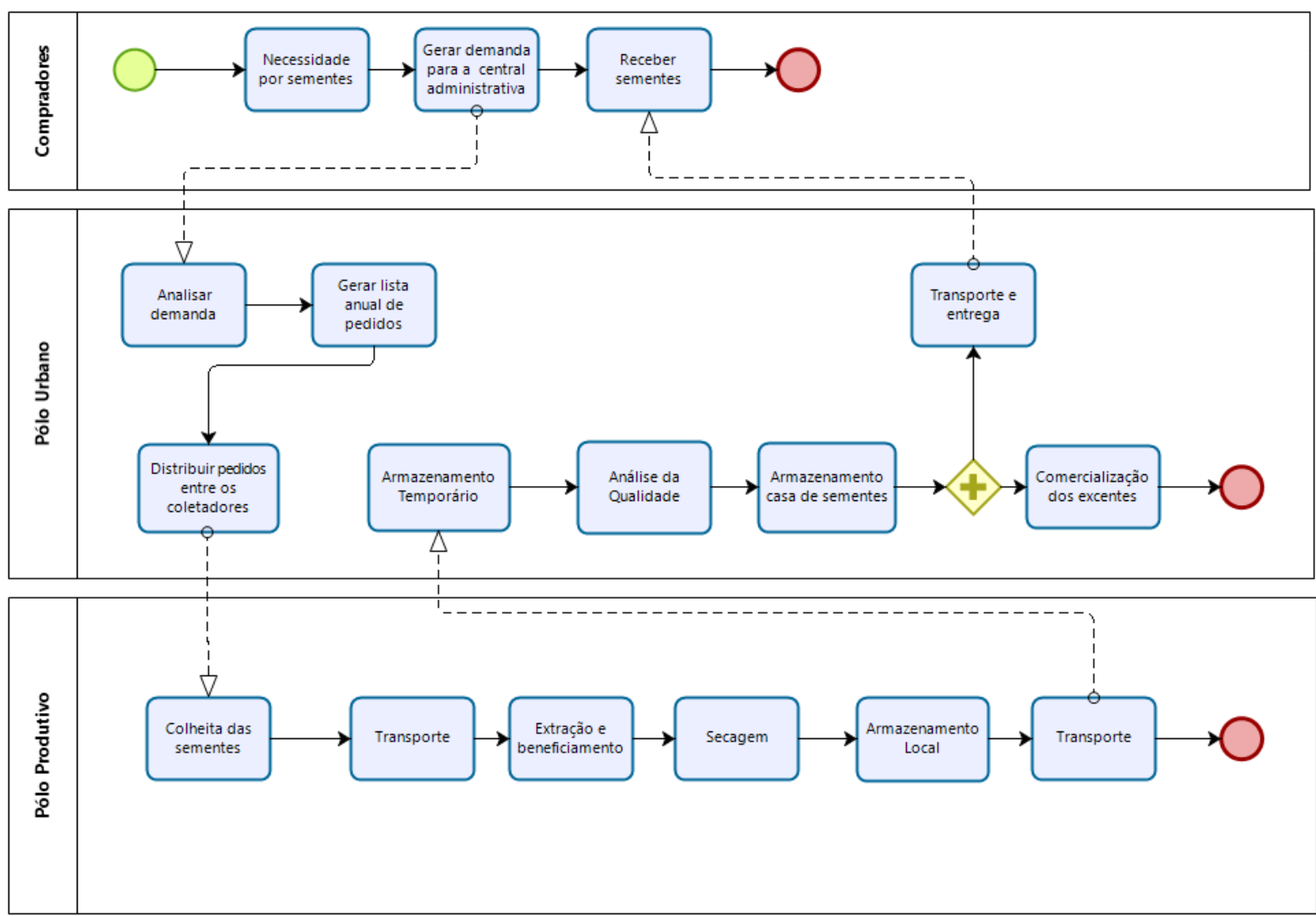

Fonte: Adaptado URZEDO, 2014.

Segundo Urzedo (2004, p. 48), o "sistema de gestão da RSX é impulsionado por uma central administrativa, a qual conta com a atuação de técnicos com a centralização dessa atividade por apenas uma das ONGs atuantes". Esse processo tem como objetivo relacionar demandas e ofertas de diferentes recursos para planejar estratégias e articular iniciativas para crescimento e fortalecimento da RSX. Operacionalmente, uma das atividades mais relevantes é o cruzamento anual da oferta de sementes indicadas pelos produtores com as demandas dos compradores. Com essas duas informações é elaborada uma meta de produção anual de sementes. Nesse sentido, a produção de sementes é integralmente comercializada sem excedentes.

Os critérios do processo de divisão da produção anual das sementes entre os coletadores seguem os parâmetros do Guia de Gestão da Rede de Sementes do Xingu, em que: 1의) se a demanda por sementes de uma espécie é maior ou igual ao potencial dos grupos, o pedido é feito para todos; 2으 se a demanda por sementes de uma espécie é um pouco menor que o potencial do grupo, diminui-se o 
pedido para todos; 3ㅇ) se a demanda por sementes de uma espécie é muito menor que o potencial dos grupos deve ser selecionado um ou dois grupos que tenham o potencial mais próximo dessa demanda; 4ํ) a distância de onde será o plantio e onde está localizado o núcleo, ou seja, quanto mais perto for o núcleo do local da entrega das sementes, maior será a possibilidade do pedido; 5ㅇ) o histórico de entrega de sementes; 6o) se o grupo não recebeu encomenda de sementes de alguma espécie, esse grupo será priorizado para a próxima espécie na sequência da divisão; 7ํ) no final da divisão dos pedidos é realizada a revisão das listas e, caso um grupo tenha recebido pouca encomenda, este será priorizado nas demandas de formação de estoque.

Nesse sentido, otimizar esse processo por meio da modelagem dinâmica, de forma que as sementes coletadas sejam integralmente comercializadas, contribui com a ampliação dos pedidos para os coletadores e, consequentemente, com todos os benefícios sociais e ambientais desse modelo de negócio. Entretanto, segundo Ticktin (2004) e Ticktin e Shackleton (2011), devem ser realizados estudos científicos que estejam comprometidos em avaliar a dinâmica funcional dos ecossistemas e das populações das espécies submetidas a diferentes intensidades de colheita de sementes florestais.

Considerando que a comercialização de sementes é afetada diretamente pelos aspectos políticos e legais desse mercado, mudanças nos códigos florestais aliadas à falta de empenho do Estado na fiscalização têm levado os infratores a não buscarem pelas sementes. Outro aspecto crítico, principalmente para os indígenas, é o transporte. Nesse processo, as distâncias geográficas para colher e escoar as sementes, a dificuldade de formar grandes lotes apontam a necessidade de investimentos em infraestrutura nos próprios núcleos coletores para garantir a condição mínima de armazenamento até que as sementes possam ser entregues para as câmaras nos centros urbanos. Mediante o exposto, melhorar esse processo por meio da modelagem, de forma a apresentar a viabilidade de armazenamentos intermediários, contribui para a ampliação da produtividade, do número de coletadores e a para a otimização de futuras novas redes de sementes.

Na Figura 4 são apresentados gargalos da produção de sementes florestais e suas respectivas inovações demandadas com base nas experiências de produtores da RSX. 
Figura 4

Gargalos da produção de sementes florestais e suas respectivas inovações demandadas com base nas experiências de produtores da RSX

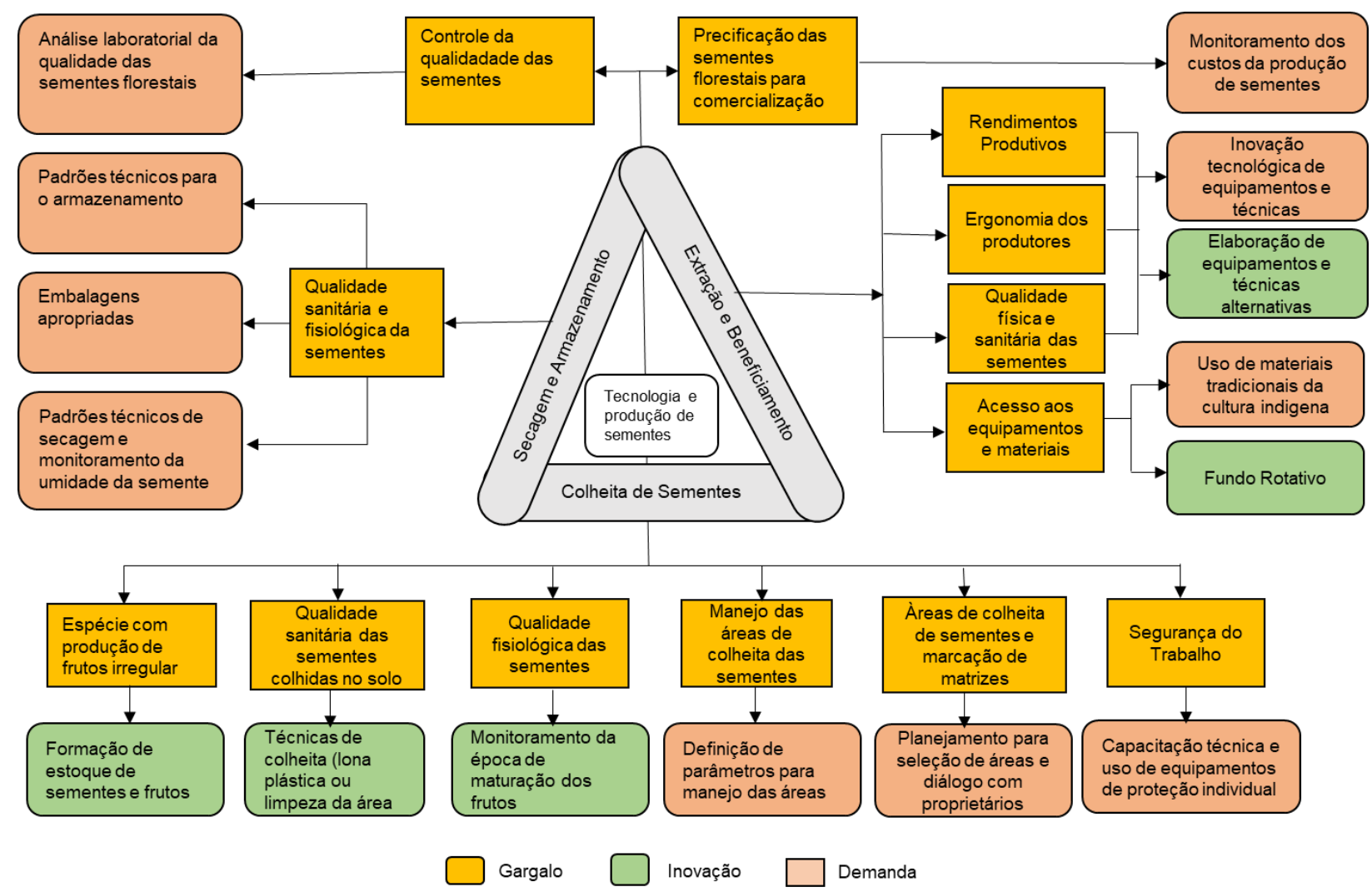

Fonte: Adaptado de Urzedo, 2014

A extração e beneficiamento de sementes florestais condicionam a produção, uma vez que o rendimento das espécies possui variação ampla, o que demanda a adoção de conhecimentos, técnicas, materiais e equipamentos de acordo com as exigências de cada uma, refletindo no tempo e dedicação empreendidos pelos coletadores. As técnicas adotadas no beneficiamento são essenciais para obtenção de sementes de qualidade física e sanitária; entretanto, o acesso às tecnologias e às técnicas foi considerado um gargalo em função da infraestrutura e do baixo grau tecnológico para semente.

As áreas de colheita de sementes florestais são manejadas a partir de diferentes compreensões quanto ao uso e conservação dos ecossistemas, e, dessa maneira, os grupos socioculturais de produtores de sementes analisados adotam técnicas de manejo florestal como alternativa para não comprometer a dinâmica dos ecossistemas e, consequentemente, manter a produção de sementes.

A secagem é a etapa determinante da produção, entretanto, verificam-se insuficiências de parâmetros técnicos nesse processo, e o mesmo ocorre com o armazenamento. O tipo de embalagem adotada pelos produtores reflete as realidades socioeconômicas, que restrigem a aquisição de 
embalagens específicas e, ou, onerosas. Os locais de armazenamento apresentam grande variação, sendo de cômodos arejados até geladeiras.

Nos casos de longos períodos de armazenamento poderá ocorrer a perda da grande quantidade de sementes em função da umidade. Esse longo tempo para escoamento da produção ocorre, principalmente, nos contextos dos agricultores familiares e indígenas, que chegam a percorrer de 50 a $450 \mathrm{Km}$

\section{Aplicação do questionário e discussão dos resultados}

A hipótese de elaboração do contexto organizacional seguindo os requisitos da NBR ISO 9001:2015 por meio de informações documentais relativas à cadeia de valor da RSX necessitou ser validada.

Dúvidas poderiam ser geradas devido à inexistência de consultas diretas aos operadores da Rede, visitas in loco, bem como pela quantidade de evidências necessárias para garantir a aderência do contexto organizacional aos critérios da norma ISO 9001:2015. A aplicação segue as cinco etapas apresentadas na Figura 5.

Figura 5

Fluxo do processo elaboração questionário

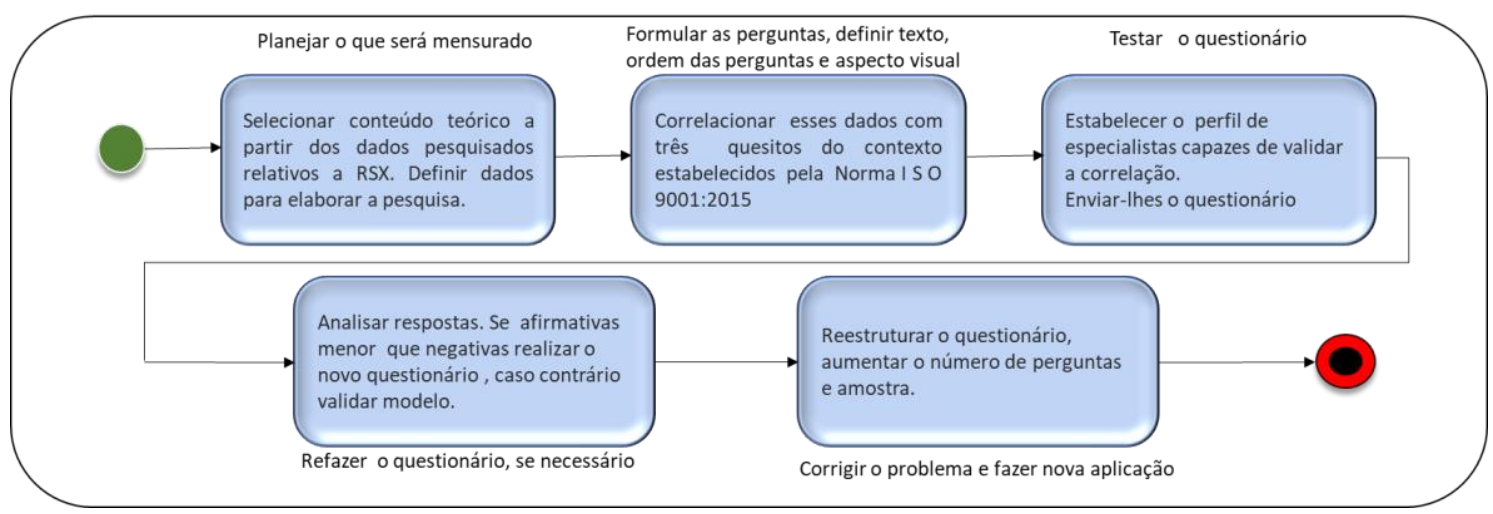

Fonte: Da autora, 2020.

Foram selecionadas três informações sobre a RSX para elaboração do questionário: uma relacionada ao propósito da rede, outra sobre as perpectivas de mercado que a rede atende e, por fim, apresentaram-se os garagalos da RSX. A partir dessas informações, o entrevistado deveria responder se o conteúdo do texto expunha informações suficientes para aplicação do requisito 4.1 e do requisito 6.1 da ISO 9001:2015.

Foram definidos10 especialistas para responder a pesquisa e, de acordo com o fluxo do processo (FIG. 5), uma vez que as pesquisas retornaram com índice de $100 \%$ de afirmação, não foi 
necessária a aplicação de novos questionários. Os nomes dos entrevistados, bem como suas experiências e formação estão disponíveis nos questionários respondidos.

Assim, conclui-se que é possível, por meio de informações documentais relativas à cadeia de valor da RSX, elaborar o contexto organizacional que compreende a elaboração da missão, visão, planejamento estratégico e gestão de riscos.

\section{Elaboração do planejamento estratégico}

Para elaboração do contexto organizacional baseado nos quesitos da norma ISO 9001:2015, a organização deve estabelecer sua missão e visão e, a partir dessas informações, descrever os pontos fortes e fracos, oportunidades e ameaças que poderiam afetar positiva ou negativamente o cumprimento dessa missão e o atingimento da visão. Com base na análise documental quanto à RSX foi possível estabelecer a visão, missão e análise do ambiente interno e externo da rede de sementes, descritos da seguinte forma:

- Missão: fornecer matéria-prima suficiente em qualidade e quantidade, de forma a garantir a manutenção da biodiversidade da floresta amazônica; fornecer subsídios para o cumprimento da legislação e propiciar aos coletadores empoderamento social e a todos os brasileiros a possibilidade de ver as florestas ressurgindo.

- Visão: ser referencial mundial no apoio ao reflorestamento e integração social com a comercialização de sementes nativas, implementando, até 2021, mais 10 unidades da rede ou similares em gestão e produção, de modo a dobrar a capacidade de fornecimento de sementes.

- Pontos fortes: conhecimento tradicional sobre as variedades de características da ecologia das espécies (principalmente entre os indígenas); o Manual Guia de Gestão da Rede de Sementes do Xingu; o livro Coletar, Manejar e Armazenar: as Experiências da Rede de Sementes do Xingu; oficinas de capacitação; vídeos-documentários; calendários para monitoramento e planejamento das colheitas; aumento contínuo da produtividade; o fluxo do processo descrito nos documentos da RSX; capacidade de cumprimento de metas.

- Pontos fracos: controle da qualidade de sementes; dificuldades de precificação das sementes florestais para comercialização; baixos rendimentos produtivos; segurança do trabalho; qualidade física e sanitária das sementes; acesso aos equipamentos e materiais para coleta e beneficiamento das sementes; dificuldades de mapeamento das áreas de colheita de sementes e marcação de matrizes manejo das áreas de colheita; qualidade sanitária e fisiológica das sementes; armazenamento inadequado de sementes e longas distâncias a 
serem percorridas até as câmaras nos centros urbanos; necessidade de inovação técnica e tecnológica para a produção de sementes.

- Ameaças: diminuição das fiscalizações; interferência política; inexistência de políticas públicas efetivas para apoiar a manutenção da rede.

- Oportunidades: legislação ambiental; interesse crescente da sociedade sobre a importância da floresta e sobre o aumento do desmatamento; apoio financeiro do fundo da Amazônia.

\subsection{Desdobramento estratégico e definição de objetivos e metas}

Apesar de todas as informações serem relevantes para a estruturação do contexto organizacional, a elaboração de objetivos que remetem às tentativas para eliminar ou gerenciar a totalidade dos pontos fracos e ameaças, monitorar forças e implementar oportunidades foram priorizadas aquelas de maior articulação com o objetivo deste artigo. As demais informações apresentam-se como demandas para estudos futuros.

\section{Quadro 4}

\section{Ações estratégicas}

\section{Proposta 1}

Objetivo estratégico 1: Criar estruturas com ambiente controlados intermediários entre o ponto de armazenamento sob responsabilidade do coletador e as casas de sementes nos centros urbanos

Objetivo estratégico 2: Otimizar o transporte

Meta 1: Reduzir a perda de sementes por acondicionamento inadequado

Meta 2: Utilizar drones para transporte similar aos utilizados pela Biocarbon Engineering

Dimensão: Fraqueza

Descrição: Armazenamento inadequado de sementes e longas distâncias a serem percorridas até as câmaras nos centros urbanos

\section{Proposta 2}

Objetivo estratégico 3: Criar estrutura similar ao Smartagro e Redes Inteligentes

Meta 3: Monitorar remotamente dados sobre as sementes, pontos de coletas, armazenamento, produtividade das semeaduras.

Dimensão: Fraqueza

Descrição: Dificuldades de mapeamento das áreas de colheita de sementes e marcação de matrizes

Proposta 3

Objetivo estratégico 4: Modelar a cadeia de valor da Rede de Sementes do Xingu

Meta 4: Otimização de processos e estudo de viabilidades para aumentar a produtividade

Dimensão: Fraqueza

Descrição: Baixos rendimentos produtivos

Objetivo estratégico 5: Utilizar a modelagem dinâmica para formação de para o processo de formação de

pedidos

Meta: Otimizar o processo de precificação

Dimensão: Fraqueza

Descrição: Dificuldades na precificação das sementes florestais para comercialização

Fonte: Da autora, 2020. 


\subsection{Ações para abordar riscos e oportunidades}

A gestão de riscos por meio da análise de sua classificação permite o estabelecimento de prioridades em função do potencial de dano na ocorrência da efetivação do risco. Para atendimento ao requisito da NBR ISO 9001:2015 convém que as ações tomadas para abordar riscos e oportunidades sejam apropriadas ao impacto potencial sobre o propósito da organização e seu direcionamento estratégico.

\subsection{Parâmetros para montagem da Matriz de Risco}

O parâmetro severidade está associado ao grau do dano que ocorrerá sobre a direção estratégica caso a fraqueza se concretiza. A análise da probabilidade foi desdobrada em dois fatores: conhecimento e controle. Esse desdobramento se deu para evitar que o fator experiências ocorridas influenciasse na quantificação da mesma, uma vez que, caso necessário, a aplicação desse modelo na criação de novas redes poderia levar a uma avaliação inconsistente da probabilidade. Assim, os valores atribuídos ao conhecimento e controle foram obtidos correlacionando as informações disponíveis sobre a RSX e a descrição da fraqueza e de acordo o Figura 6.

\section{Figura 6}

\section{Parâmetros para gradação do risco}

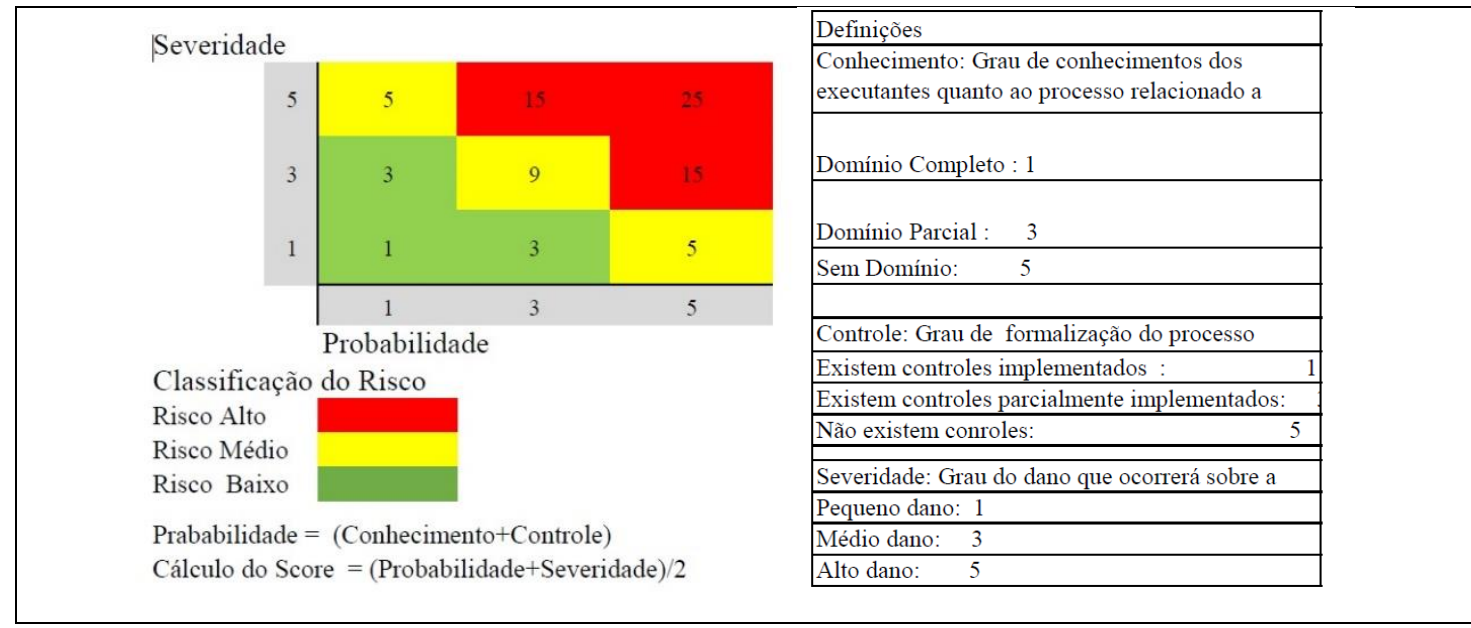

Fonte: Da autora, 2020.

Baseando-se nessa condição e por meio das ações estratégicas da RSX, apresentadas no Quadro 4, foi elaborada a matriz Gestão de Risco Desdobramento da Análise do Ambiente Fraquezas. 


\section{Quadro 6}

Matriz de Risco Desdobramento da Análise do Ambiente - Fraquezas

\begin{tabular}{|c|c|c|c|c|c|c|c|c|}
\hline \multirow{2}{*}{$\begin{array}{l}\text { Descrição da } \\
\text { Fraqueza }\end{array}$} & \multirow{2}{*}{ Objetivo Estratégico } & \multirow{2}{*}{ Meta } & \multirow{2}{*}{ Riscos } & \multirow{2}{*}{ Severidade } & \multicolumn{2}{|c|}{ Probabilidade } & \multirow{2}{*}{ Score } & \multirow{2}{*}{$\begin{array}{c}\text { Classificação } \\
\text { do Risco }\end{array}$} \\
\hline & & & & & Conhecimeto & Controle & & \\
\hline $\begin{array}{l}\text { Armazenamento } \\
\text { inadequado de } \\
\text { sementes e } \\
\text { longas } \\
\text { distâncias a } \\
\text { serem } \\
\text { percorridas até } \\
\text { as câmaras nos } \\
\text { centros urbanos }\end{array}$ & \begin{tabular}{|l|} 
Criar estruturas \\
com ambiente \\
controlados \\
intermediários \\
entre o ponto de \\
armazenamento \\
sob \\
responsabilidade \\
do coletador e as \\
casas de sementes \\
nos centros \\
urbanos
\end{tabular} & $\begin{array}{l}\text { Reduzir a perda de } \\
\text { sementes por } \\
\text { acondicionamento } \\
\text { inadequado }\end{array}$ & $\begin{array}{l}\text { Aumentar o } \\
\text { preço das } \\
\text { sementes } \\
\text { Perda de } \\
\text { sementes } \\
\text { coletadas }\end{array}$ & 3 & 1 & 3 & 6 & Médio \\
\hline $\begin{array}{l}\text { Dificuldades de } \\
\text { mapeamento } \\
\text { das áreas de } \\
\text { colheita de } \\
\text { sementes e } \\
\text { marcação de } \\
\text { matrizes }\end{array}$ & \begin{tabular}{|l|} 
Criar estrutura \\
similar ao \\
Smartagro e Redes \\
Inteligentes
\end{tabular} & $\begin{array}{l}\text { Monitorar } \\
\text { remotamente } \\
\text { dados sobre as } \\
\text { sementes, pontos } \\
\text { de coletas, } \\
\text { armazenamento, } \\
\text { produtividade das } \\
\text { semeaduras. }\end{array}$ & \begin{tabular}{|l|} 
Reduzir a \\
capacidade de \\
produção
\end{tabular} & 3 & 3 & 3 & 9 & Médio \\
\hline $\begin{array}{l}\text { Baixos } \\
\text { rendimentos } \\
\text { produtivos }\end{array}$ & $\begin{array}{l}\text { Modelar a cadeia } \\
\text { de valor da Rede } \\
\text { de Sementes do } \\
\text { Xingu }\end{array}$ & $\begin{array}{l}\text { Otimização de } \\
\text { processos da } \\
\text { cadeia de } \\
\text { suprimentos } \\
\text { visando aumentar } \\
\text { a produtividade }\end{array}$ & $\begin{array}{l}\text { Inexistir tipos } \\
\text { específicos de } \\
\text { sementes para } \\
\text { reflorestar } \\
\text { Perda da } \\
\text { biodiversidade }\end{array}$ & 5 & 3 & 3 & 15 & Alto \\
\hline $\begin{array}{l}\text { Dificuldades na } \\
\text { precificação } \\
\text { das sementes } \\
\text { florestais para } \\
\text { comercialização }\end{array}$ & \begin{tabular}{|l|} 
Utilizar a \\
modelagem \\
dinâmica para \\
formação de para o \\
processo de \\
formação de \\
pedidos
\end{tabular} & $\begin{array}{l}\text { Otimizar o } \\
\text { processo de } \\
\text { precificação }\end{array}$ & \begin{tabular}{|l} 
Possibilitar \\
fraudes \\
Possibiltar \\
suborno \\
Aumento \\
inadequado dos \\
preços
\end{tabular} & 5 & 3 & 1 & 10 & Médio \\
\hline
\end{tabular}

Fonte: Da autora, 2020.

O parâmetro severidade está associado ao grau do dano que ocorrerá sobre a direção estratégica, caso a fraqueza se concretiza. A análise da probabilidade foi desdobrada em dois fatores: conhecimento e controle. Esse desdobramento se deu para evitar que o fator experiências ocorridas influenciasse a quantificação da mesma, uma vez que, caso necessário, a aplicação desse modelo na criação de novas redes poderia levar a uma avaliação inconsistente da probabilidade. Assim, os valores atribuídos ao conhecimento e controle foram obtidos correlacionando as informações disponíveis sobre a RSX e a descrição da fraqueza.

Levando em consideração os fatores apresentados é possível apresentar a proposta de que as ações prioritárias para desenvolver o objetivo estratégico 5 - utilizar a modelagem dinâmica para o 
processo de formação de pedidos - e o objetivo estratégico 4 - modelar a cadeia de valor da Rede de Sementes do Xingu - sejam implementados. Essa proposta, além de gerar ganhos para RSX com a mitigação ou redução das fraquezas relacionas, certamente apoiaria a implementação de novas redes dentro do objetivo proposto por este artigo.

\section{Discussão dos resultados}

As sementes nativas são consideradas essenciais no plantio ou replantio de florestas. A comercialização eficaz dessas sementes é necessária como forma de garantir a disponibilidade da matéria-prima em quantidade e qualidade adequadas para o reflorestamento. O elo entre os compradores de sementes e o processo produtivo é realizado por uma cadeia de agentes estruturados em uma rede. Entretanto, a autossustentabilidade desse tipo de negócio é baixa, o que gera o encerramento precoce do mesmo. Todavia, uma rede denominada Rede de Sementes do Xingu se mantém ativa e gerando resultados efetivos.

Ao analisar, com base nos quesitos de estratégia NBR ISO 9001:2015 e de gestão de riscos da NBR I S O 31000, os pontos fortes e fracos, ameaças e oportunidades, bem como os riscos associados ao propósito e direcionamento estratégico da RSX, foi possível compreender a dinâmica dessa rede e proporcionar, por meio da elaboração da matriz de riscos, a apresentação de objetivos e metas capazes de reforçar a perenidade da RSX.

Foram identificados no processo de gestão de risco, quatro riscos, sendo três classificados como médio e um como alto.Para este, ou seja, inexistir tipos específicos de sementes para reflorestar e perda da biodiversidade da floresta amazonica foi proposto como tratamento a otimização de processos da cadeia de suprimentos. Os riscos médios, aumento do preço das sementes, perda de sementes coletadas e possibilidades de suborno, tem proposta de tratamentos baseados na modelagem dos processos para a cadeia de valor da RSX e um projeto de armazenamento e controle próximo às áreas de coleta.

Foi possível, também, verificar a viabilidade de aplicação desse documento quando da abertura de novas redes A necessidade de suprir o mercado face ao aumento do desmatamento impõe uma urgência na abertura de, pelo menos, 50 novas redes.

Além do aspecto comercial verificou-se, também, o relevante papel da RSX no âmbito social, uma vez que ela tem proporcionado melhorias na qualidade de vida de cerca de 600 coletadores indígenas, assentados e ruralista que atuam na rede. Com a abertura e manutenção da estrutura, novos coletadores teriam a capacidade de se integrar ao mercado de trabalho.

A discussão sobre este tema é fundamental, uma vez que hoje sobram sementes nos depósitos dos coletadores, redes são encerradas e, mesmo para RSX, um caso de sucesso, gargalos, como 
formação de preços armazenamento e transporte, levam à perda dessas sementes. Não utilizar todas as sementes disponíveis é desperdiçar um bem extremamente precioso para a humanidade e para o meio ambiente. Outro aspecto relevante passível de análise é a possibilidade de aumentar o número de coletadores que têm nessa profissão uma forma de melhorar a qualidade de vida e gerar renda.

\section{Conclusões}

Ao concluir de forma efetiva o objetivo deste artigo, expondo a abordagem estratégica e gestão de risco previstas na elaboração do contexto organizacional, baseado nos requisitos da ISO 9001:2015 para a Rede de Sementes do Xingu, é possível vincular a RSX a uma organização produtiva e eficaz, uma vez que empresas de sucesso são capazes de elaborar um planejamento estratégico dinâmico e efetivo, avaliar os riscos do negócio, bem como gerenciar de forma sistêmica seus processos e interações.

Assim, estabelecer novas redes baseadas nesse modelo torna tangível a garantia de perenidade das mesmas. Como resultado, tem-se expansão dos benefícios sociais com a geração de vagas para coletadores, a salvaguarda do processo de reflorestamento e a promoção da manutenção da biodiversidade da floresta amazônica.

O poder público/privado, face aos problemas do desmatamento e empregabilidade, precisa ampliar a visão sobre a importante atuação das redes de sementes nativas e possibilitar a ampliação de modelos como os da RSX. A reprodução dessas unidades tem um elementar facilitador apresentado neste artigo, que é o nexo com os parâmetros de risco e estratégia da NBR ISO 9001:2015.

Devido à limitação de estudos relacionados ao tema, a abrangência das informações descritas neste artigo pode não revelar todas a características a respeito da RSX. Outro elemento a ser considerado é que não foram encontrados artigos que apresentassem os motivos de encerramento das demais redes, o que poderia contribuir com a elaboração dos aspectos estratégicos apresentados neste artigo.

Outra aspecto que deve ser considerado para estudos fututros a implementação dos tratamentos propostos: a otimização de processos da cadeia de suprimentos, a modelagem dos processos para a cadeia de valor da RSX e um projeto de armazenamento e controle próximo às áreas de coleta.

Frente ao apresentado e considerando a relevância do tema, propõe-se, para estudos futuros, o desdobramento em ações dos objetivos e metas descritos. Convém que sejam priorizadas a utilização da modelagem dinâmica para o processo de formação de pedidos e a modelagem para a cadeia de valor da Rede de Sementes do Xingu. Essa proposta, além de gerar ganhos para RSX, com a mitigação ou redução das fraquezas relacionas, certamente apoiaria a implementação de novas redes dentro do objetivo proposto por este artigo. 


\section{Referências}

Aaker, D. A., Kumar, V., \& Day, G. S. (2001). Marketing research (7th ed.). New York: John Wiley \& Sons, Inc.

Aguiar, E. C. (2010). Contribuição ao estudo do fator risco no desempenho de organizações e cadeias de suprimentos. Tese de doutorado, Faculdade de Economia, Administração e Contabilidade, Universidade de São Paulo, São Paulo.

Akao, Y. (1996). Introdução ao desdobramento da qualidade (Z. T. Fujikawa e S. Takahashi, Trad.) Belo Horizonte, Escola de Engenharia da UFMG, Fundação Cristiano Ottoni.

Associação Brasileira de Normas Técnicas. (2015). ABNT NBR ISO 9001:2015: Sistemas de gestão da qualidade - requisitos. Rio de Janeiro.

Barnett, J. P., \& Baker, J. B. (1991). Regeneration methods. In M. L. Duryea \& P. M. Dougherty (Eds.). Forest regeneration manual. (pp. 35-55). Dordrecht: Kluver Academic Publishers.

Bechara, E. Uma contribuição ao aprimoramento do instituto da compensação ambiental previsto na lei 9.985/2000. 2007. 352p. Tese (Doutorado) - Pontifícia Universidade Católica de São Paulo, São Paulo. Disponível em:

http://www.dominiopublico.gov.br/download/teste/arqs/cp041032.pdf

Besanko, D., Dranove, D., \& Shanley, M. (2000). Economics of strategy. New York: John Wiley and Sons.

Brasil. (1981). Lei no 6.938, de 31 de agosto de 1981. Dispõe sobre a Política Nacional do Meio Ambiente, seus fins e mecanismos de formulação e aplicação, e dá outras providências, Brasília.

Brasil. (1998). Lei no 9.605, de 12 de fevereiro de 1998 Dispõe sobre as sanções penais e administrativas derivadas de condutas e atividades lesivas ao meio ambiente, e dá outras providências, Brasília.

Brasil. (2000). Lei Federal no 9.985, de 18 de julho de 2000. Regulamenta o art. 225, § 1으, incisos I, II, III e VII da Constituição Federal, institui o Sistema Nacional de Unidades de Conservação da Natureza e dá outras providências, Brasília.

Brasil. (2008). Ministério do Meio Ambiente. Consultoria Jurídica. Legislação Ambiental Básica / Ministério do Meio Ambiente. Consultoria Jurídica. Brasília: Ministério do Meio Ambiente, Unesco.

Brasil. (2012). Lei n. 12.651, de 25 de maio de 2012. Dispõe sobre a proteção da vegetação nativa; altera as Leis nos 6.938, de 31 de agosto de 1981, 9.393, de 19 de dezembro de 1996, e 11.428, de 22 de dezembro de 2006; revoga as Leis nos 4.771, de 15 de setembro de 1965, e 7.754, de 14 de abril de 1989, e a Medida Provisória no 2.166-67, de 24 de agosto de 2001; e dá outras providências. Brasília: Diário Oficial da União.

Carneiro, M. A., Costa, F. H. O., Gilberto, T. M. J., \& Tomas, R. N. (2019). Gerenciamento de riscos para a cadeia de suprimentos: uma revisão sistemática de literatura. Produção Online, 19(3), 10481068. 
Cheng, L. C., Scapin, C. A., Oliveira, C. A., Krafetuski, E., Drumond, F. B., Boan, F. S., Prates, L. R., \& Vilela, R. M. (1995). QFD: planejamento da qualidade. Belo Horizonte, UFMG, Escola de Engenharia, Fundação Cristiano Ottoni.

Chopra, S., \& Meindl, P. (2013). Supply chain management strategy, planning, and operation. England: Pearson Education Limited.

Christopher, M., \& Lee, H. L. Mitigating supply chain risk through improved confidence. (2004). International Journal of Physical Distribution \& Logistics Management, 34(5), 388-396.

Collier, P. M. (2009). Fundamentals of risk management for accountants and managers. New York: Routledge.

Committee of Sponsoring Organizations of the Treadway Commission [COSO]. (2013). Internal Control - Integrated Framework.

Easterby-Smith, M., Thorpe, R., \& Lowe, A. (1999). Management research: an introduction. London: Sage.

Faria, I. D. (2008). Compensação ambiental: os fundamentos e as normas; a gestão e os conflitos. Consultoria Legislativa do Senado Federal, Brasília. Recuperado de: http://www2.senado.leg.br/bdsf/handle/id/99899

Ferreira, R. A., Davide, A. C., Motta, M., \& Bearzoti, E. (2007). Semeadura direta com espécies arbóreas para recuperação de ecossistemas florestais. Cerne, 13(3), 271-279.

Ferreira, R. A., Santos, P. L., Aragão, A. G., Santos, T. I. S., Santos, E. M., Neto, \& Rezende, A. M. S. (2009). Semeadura direta com espécies florestais na implantação de mata ciliar no Baixo São Francisco em Sergipe. Scientia Forestalis, 37(81), 37-46.

Gil, A. C. (2017). Como elaborar projetos de pesquisa (6a ed.). São Paulo: Atlas.

Hayne, C., \& Free, C. (2014). Hybridized professional groups and institutional work: COSO and the rise of enterprise risk management. Accounting, Organization and Society, 39(5), 309-333.

Huber, C., Scheytt, T. (2013). The dispositif of risk management: reconstructing risk management after the financial crisis. Management Accounting Research, 24(2), 88-99.

Jüttner, U., Peck, H., \& Christopher, M. (2003). Supply chain risk management: outlining an agenda for future research. International Journal of Logistics: Research and Applications, 6(4), 197-210.

Kern, D., Moser, R., Hartmann, E., \& Moder, M. (2012). Supply risk management: model development and empirical analysis. International Journal of Physical Distribution \& Logistics Management, 42(1), 60-82. https://doi.org/10.1108/09600031211202472

Kintish, E. (2007). Carbon emissions: improved monitoring of rainforests helps pierce haze of deforestation. Science, 316(5824), 536-537. Disponível em: http://www.obt.inpe.br/OBT/assuntos/programas/amazonia/prodes/pdfs/kintish_2007.pdf

Le Tourneau, F. M., Bursztyn, M. (2010). Assentamentos rurais na Amazônia: contradições entre a política agrária e a política ambiental. Ambiente \& Sociedade, Campinas, 13(1), 111-130. 
Lopes, L. C. P., \& Gomes, M. F. (2017). Revista Direito Ambiental e Sociedade, | 7(3), 105-127.

Manuj, I., \& Mentzer, J. T. (2008). Global supply chain risk management strategies. International Journal of Physical Distribution \& Logistics Management, 38(3), 192-223. https://doi.org/10.1108/09600030810866986

Matos, A. L. T., Vitorino, V. A., Filho, Spers, V. R. E., \& Pires, S. R. I. (2017). A produção acadêmica internacional sobre gestão de riscos na cadeia de suprimentos no período entre 2005 e 2014. Revista de Administração Faces Journal, Belo Horizonte, 16(1), 45-65.

Mattei, V. L. Agentes limitantes a implantação de Pinus taeda L. por semeadura direta. (1995). Ciência Florestal. Santa Maria, 5(1), 9-18.

Olechowski, A., Oehmen, J., Seering, W., \& Ben-Daya, M. (2016). The professionalization of risk management: What role can the ISO 31000 risk management principles play? International Journal of Project Management, 34(8), 1568-1578.

Perez-Aleman, P. (2010). Collective learning in global diffusion: spreading quality standards in a developing country cluster. Organization Science, 22(1), 173-189.

Sachs, I. (2009). A terceira margem: em busca do ecodesenvolvimento. São Paulo: Companhia das Letras.

Salgado, E. G., Anjos, F. H. dos, Silva, V. N. da, Souza, M. de, Sant'ana, T. D., Bermejo, P. H. S., Mendonça, L. C., \& Pinheiro, I. F. (2019). Systematic Literature Review of the Risk Management Process Literature for the Public Sector. In: Yang XS., Sherratt S., Dey N., Joshi A. (Eds) Third International Congress on Information and Communication Technology. Advances in Intelligent Systems and Computing, v. 797. Springer, Singapore. https://doi.org/10.1007/978-981-13-1165-9_78

Sanches, R. A. (2015). Campanha 'Y Ikatu Xingu: governança ambiental da região das nascentes do Xingu (Mato Grosso, Brasil). Tese (Doutorado em Ambiente e Sociedade), Instituto de Filosofia e Ciências Humanas, Universidade Estadual de Campinas, Campinas, Brasil.

Santos, N. A., Jr., Botelho, S. A., \& Davide, A. C. (2004). Estudo da germinação e sobrevivência de espécies arbóreas em sistema de semeadura direta, visando à recomposição de mata ciliar, Cerne, 10(1), 103-117.

Saunders, M., Lewis, P., \& Thornhill, A. (2012). Research methods for business students. Pearson Education Ltd.: Harlow.

Scheytt, T., Soin, K., Sahlin-Andersson, K., \& Power, M. (2006). Introduction: organizations, risk and regulation. Journal of Management Studies, 43(6), 1331-1337.

Tang, C., \& Musa, N. (2011). Identifying risk issues and research advancements in supply chain risk management. International Journal of Production Economics, 133(1), 25-34.

Thekdi, S., \& Aven, T. (2016). An enhanced data-analytic framework for integrating risk management and performance management. Reliability Engineering \& System Safety, 156, 277-287. https://doi.org/10.1016/j.ress.2016.07.010. 
Themsen, T. N., \& Skærbæk, P. (2018). The performativity of risk management frameworks and technologies: the translation of uncertainties into pure and impure risks. Accounting, Organizations and Society. https://doi.org/10.1016/j.aos.2018.01.001

Ticktin, T. (2004). The ecological implications of harvesting, non-timber forest products. The journal of Applied Ecology, Oxford, 41, 11-21.

Ticktin, T., \& Shackleton, C. (2011). Harvesting non-timber forest products sustainably: Opportunities and challenges. In S. Shackleton, C. Shackleton, P. Shanley. (Eds.). Non-timber forest products in the global context (pp. 149-169). Heidleberg: Springer.

Tomas, R. N., \& Alcantara, R. L. C. (2013). Modelos para gestão de riscos em cadeias de suprimentos: revisão, análise e diretrizes para futuras pesquisas. Gestão \& Produção, 20(3), 695-712. https://doi.org/10.1590/S0104-530X2013000300014

Uhl, C., Da Silva, J. M. C., Nepstad, D. C., \& Vieira, I. C. G. (1991). Restauração da floresta em pastagens degradadas. Ciência Hoje, 13(76), 23-31.

Urzedo, D. I. de. (2014). Trilhando recomeços: a socioeconomia da produção de sementes florestais do Alto Xingu na Amazônia brasileira. Piracicaba. Tese de Doutorado, Escola Superior de Agricultura Luiz de Queiroz, Universidade de São Paulo, São Paulo, Brasil.

Urzedo, D. I. de. (2017). Organização comunitária para as sementes florestais no Xingu-Araguaia. Informativo ABRATES, Londrina, 27(2), 37.

World Wildlife Fund. (2018). Maior aumento de desmatamento da Amazônia em dez anos. [S. I.]: WWF Brasil. Recuperado de: https://www.wwf.org.br/?68662/maior-aumentodesmatamento-amazonia-dez-anos

Wu, D. D., \& Olson, D. L. (2010). Introduction to special section on "Risk and technology". Technological Forecasting and Social Change, 77(6), 837-839.

Yin, R. K. (2005). Estudo de caso: planejamento e métodos (3a ed.). Porto Alegre: Bookman. 